\title{
A Phenomenological Study of Education for Sustainable Development in Higher Education of Pakistan
}

\author{
Sehrish Khan ${ }^{*}$ \\ Ayaz Muhammad Khan ${ }^{* *}$
}

\begin{abstract}
Sustainable development in higher education is still at infancy stage while the aim was to train our youth to be sustainable leaders for ensuring conservation of the environment, society and economy for future. The leading purpose of the paper was to unfold the situation of five universities for the level of embeddedness of education for sustainable development in preparing their students as sustainable leaders. The nature of the study was qualitative and phenomenological approach through semi-structured interviews (validated by four experts of related field) conducted from department heads of universities present in Lahore. Three themes (along with sub exclusive functionalities of the university) were noted during qualitative analysis of the collected data. The findings indicated various levels of embeddedness of education for sustainable development i.e. high, medium or low in the form of three pillars of sustainability (economic, social and environmental), in the university education and research, university operations and external community.
\end{abstract}

Keywords: sustainable development, economic, social environmental, university

\footnotetext{
${ }^{*}$ Research Scholar University of Education, Lahore

** Associate professor: University of Education Lower Mall Campus Lahore Email: ayaz@ue.edu.pk
} 


\section{Introduction}

Sustainable development was foremost defined by the Brundtland Commission as a package of resources i.e. ecological, social and economical which are capable of satiating the present needs without endangering the capability of upcoming generations for fulfilling their own needs (WCED, 1987). These three factors are interdependent on each other in order to harmonize the world's sustainability. Learning must be taken place according to this sustainability concept while transforming behaviours of the population towards the sensitivity of the issue; this can only be done with the help of awareness campaigns and formal and informal education(Khalifa \& Sandholz, 2012). The role of this proposition at higher education is more crucial than compulsory education due to the fact that at this stage students have chosen their career orientation while they would be going to put their first step in labour and competitive market adorned with skill to earn their livelihood while if this young labour also prove themselves as sustainable leaders ensuring sustainability of their surroundings then higher education would ultimately deliver its best on the issue. That is why a broad debate had been identified among educationists and researchers about the competencies that they should be adorned with at the end of their university education (Wiek, Withycombe, Redman, \& Mills, 2011).Weik et al (2012) discussed these skills as an open plan of action for formulating courses of academic programs in which clear reference and particulars about training should also be represented in relation to overall development of a graduate; progress at each phase of learning as well as effective pedagogies for fulfilling this need; reliable and appropriate resources for students in order to assist them in performing their professional actions currently and also for future problem resolution, they could act as change agents in order to settle conversion processes tolerably (Hidalgo \& Fuentes., 2013; Willard et al., 2010).

Thus a reason to adopt that type of education which permit universities to induct in its student's new ways of living differently i.e. be fully aware of the natural environment and its true need for us. For this purpose, some basic changes in the curriculum of universities and the role institution plays, are needed (Hidalgo \& Fuentes, 2013). The university students are needed to be trained in such a way that they can cope up with any unsustainable situation or problems. They should be able to decide what is right for future in order to lessen un-sustainability (Hidalgo \& Fuentes, 2013) and making them as sustainable leaders. 
Sustainable Development and Pakistan: A number of countries had understood and taken initiatives for the need of education for sustainable development but the situation in Pakistan is quite restricted due to the low pace of progress in arousing awareness, policy, and funding. According to State Bank Annual Report of 2009, Pakistan is among sixth largest populated countries in the world. The main barriers to the progress of Pakistan's sustainable development are poverty and illiteracy. In order for the population to be aware and conscious of the situation, education for sustainable development can play a vital role. For achieving the target government is struggling hard for raising standards of Pakistan's people and economy. With all the dimensions of sustainable development that is needed to be addressed and concerned Pakistan is taking active part in all international interventions and movements of Sustainable development and in $19^{\text {th }}$ session of UN Commission on Sustainable Development (2011), Pakistan desired that countries should become partners in fulfilling their financial constraints collectively by active transfer of technology and building capacities from developed countries to bring down the unsustainable situation towards sustainable conditions (OECD, 2011; Mustaq \& Azeem, 2012). For attaining the purpose of the study, the researcher used the phenomenological approach to explore the phenomenon of sustainable leadership in higher education. Firstly, let us take a look at what phenomenology is? And then how our study proceeded.

Who were the Founders of Phenomenology?: The idea of phenomenology was given by Edmund Husserl $(1859$ - 1938) with the crisis of ideological philosophical perspectives (Eagleton, 1983). There is another great philosopher too that were considered to be the founding members of phenomenological concepts such as Kant, Hegel but Husserl is regarded as a pioneer of $20^{\text {th }}$-century phenomenology (Vandenberg, 1997). The views of Husserl were expanded by Heidegger, Sartre \& Marleau (Speigelberg, 1982). It comes under the category of the qualitative and narrative type of study. This sort of study accounts for the narration of experiences of single or a number of individuals regarding their experienced experiences related to a particular concept or a phenomenon (Creswell, 2013). Phenomenologist aim at gathering descriptions about what participants have to tell as they undergo and experience a certain phenomenon; focusing on commonalities in their experiences (Manen, 1990). The idea behind it is to limit experiences of participants to the phenomenon and its descriptions generally in universal view; thus identifying a particular phenomenon through human experiences (Manen, 1990). The researcher gathers data from individuals 
who had undergone through the phenomenon or had experienced it, the narrations thus constituted what and how their experiences are all about (Moustakas, 1994). The current study was conducted in Educational context by the researchers.

\section{Phenomenological Research Procedure}

The methodological basis of this study traced back to the work of Moustaka's (1994) approach due to the fact that it contained systematic data analysis procedural steps. The major steps used in this study were:

1. Determining the research problem i.e. either it is best fit in phenomenological approach

2. A phenomenon to study i.e. sustainable leader in higher education; what is the level of embeddedness in higher education as well as what is further going on to train students as sustainable leaders

3. Identifying philosophical assumptions of phenomenology i.e. narrations provided by participants are lived and conscious experiences that lead towards an objective or an opinion

4. Data was gathered from the individuals who had experienced that phenomenon i.e. who either knew what is an education for sustainable development and/or what is sustainable leadership as well as who were involved in teaching or learning ESD. 25Participants were interviewed from 5 university campuses that are in between a recommended range to conduct phenomenology (Polkinghorne, 1989).

5. Collected data was thus reduced to quotes and then major themes.

6. A further step was also taken place i.e. researchers also write about their own experiences/observations as recommended in conducting phenomenology by Moustakas (1994) and also by Marshall and Rossman (2010).

Present study followed transcendental phenomenological approach as it claimed to "identify a phenomenon to study, bracketing out individuals" experiences while collecting data from a number of individuals who had experienced the phenomenon" (Moustakas, 1994). After that analysis is made by researcher through limiting the information into quotes or narrations and then amalgamates those into major themes.

\section{How this Study Opened Out?}

The paper in hand reflected the level of embeddedness of education for sustainable development in preparing their students as sustainable 
leaders. For this purpose, the work of Lambert $(2011$; 2012) was used for displaying conceptual strength towards the concepts under discussion. This article was based upon an initial sample of 25 head of departments of 5 higher education institutes present in Lahore, Punjab, who were invited to participate in interview sessions based on the semi-structured questions about the level of embeddedness of Education for sustainable development and the steps their institute usually take for the development of their students as sustainable leaders.

They were interviewed in order to gather opinions about generating sustainable leaders. Every interview transcriptions were immediately analyzed in order to search for new information. Each participant came out with some new opinion generating novel themes. Every new information, idea, concept, view or theme was also inquired from participants interviewed earlier in order to reach to the point of saturation i.e. no new information can be drawn out from the descriptions of the participants. The study was conducted in early 2016 while its discussion provides some important suggestions for the making the development of sustainable leaders in higher education institutes of Pakistan possible.

\section{Research Questions}

This study was conducted to inspect the embededness level of university leadership and to enumerate this level of embeddedness for sustainable development. What role university level leadership preforming in preparing their students as sustainable leaders and what elements were essential to the development of sustainable leadership. Faculty members were also asked to provide information regarding their perceived role in the development of sustainable leaders and to what extent education for sustainable development was embedded in their institution.

The main questions to be researched were:

1. What is the importance and need for sustainable leaders?

2. How is sustainable leadership perceived by faculty members?

3. What manner can faculty members contribute to the training of prospective teachers as sustainable leaders?

4. What is the level of ESD in faculty members' respective institutes?

\section{Review of Related Literature}

The term sustainable development had been used by almost persons of every field like economists, educationists, politicians, managers etc, 
but at first, it was mostly the debate between the people whose concerns were more economical than other pillars of sustainable development. For instance, some researchers criticized the use of sustainable concept more towards economical scenario than ecological concerns (Rauch, 2002; Elliot, 1998).The term Sustainable Development got its place internationally when it was stated in the World Conservation Strategy's document (IUCN, 1980) and after that, it was again used by the report submitted by World Commission on Environment and Development (WCED, 1987). The famous WCED definition was:

Sustainable development is a development which meets the needs of the present without compromising the ability of future generations to meet their own needs (WCED, 1987).

On the other hand Education for Sustainable Develop entails that learning is the only way by which perceptions of anyone from any field of life can be transformed and used for positive engagement in promoting sustainable world, thus, education or educating for sustainable development is a core aspect, a process, and a mean, not an end(Scott \& Gough, 2004).

\section{Higher education and sustainable development}

As discussed in numerous studies that the idea of sustainable development was first initiated at The Earth Summit (1972) at Stockholm. The stakeholders of that Summit recognized education as the key for achieving sustainable development, since then organizations and institutes are addressing sustainable development in almost every field of practice. Still, it is noticeable that the progress and development for attaining sustainability and its helping factors are insufficient (UNESCO, 2012). The prominent and main goal of Education for sustainable development stated in DESD was, "integrate the principles, values, and practices of sustainable development into all aspects of education and learning. "Moreover, it also anticipated that such an intervention would "encourage changes in behaviour that will create a more sustainable future in terms of environmental integrity, economic viability, and a just society for present and future generations."

The philosophy behind this encouragement was that learning and altering human behaviour in order to check and eradicate hazardous effects on all three contributors to sustainable development. Today that

philosophy had transformer more than that of a mere concept of preserving the environment it rather includes how population and 
communities can act towards sustainability and interact with the Earth in a friendly way; giving birth to the concept of sustainable leaders/change agents.

\section{Conceptual Underpinnings}

With the emergence of latest trends in sustainable development in education, sustainable educational leadership is getting more attention and considerations while Owens and Valesky (2011) declared that all stakeholders of an educational institute should give a maximum attention to the overall environment (either academic or non-academic) of an institute in order to gain sustainable leadership in education. This would adorn an institute with liability, strength and enhancements.

\section{Defining Sustainable Leadership}

One of the pioneers of the concept of sustainable leadership Hargreaves and Fink (2004) stated sustainability as a collective responsibility of checking and eradicating the continuous loss of all types of resources available within this globe like financial, ecological, social etc with the help of strong leadership in the educational communitybased environment. On the other hand, some of the experts considered the role of sustainable leadership far more than temporary achievements towards long-lasting impacts on learning of individuals so that they can act as continuous change agents for the implementations and improvements (Glickman, 2002; Stoll, Fink \& Earl, 2002). The scholars like Fullan (2005) took the view of sustainable leadership more of valuebased than that of learning i.e. to promote humanity and equality within the framework.

\section{Principles of Sustainable Leadership}

Sustainable leadership is still not a mature concept with the discovered literature on this topic was not of before 2003. That literature was found in basic education and high schools but not on further education or higher levels (Lambert, 2012) while Lambert tried to transfer as a whole or in parts to further education. According to Magnus (2009), the factors of inefficient dissipation of education are due to the population that delivering education; those stakeholders are usually aged and lagging behind in acquiring latest leadership qualities. 
Hargreaves and Fink (2006) designed a model for introducing sustainable leadership in already operating leadership practices of an organization. In their point of view in an organizational level of leadership; economy matters more, but sustainable leadership is not responsible of adorning with short-term fixtures rather is future plus long-term oriented, in this way it is significant to note that the head of departments/principals or the authority who is beholding the ordering chair is capable enough to anticipate future strength and weaknesses or not. They exclaimed that this kind of check and balance on the head seat will be able to provide fruits like producing individuals with hands-on continuous professional development in order to attain a significant position as a leader as well as long-lasting stability and maintenance of an organization. The model presented by Hargreaves and Fink was encapsulated in seven basic principles; being one of the most famous principles for sustainable leadership (2003) named as the "Seven Principles of Sustainable Leadership". The principles declare that sustainable leadership;

1. is responsible for generating and conserving sustainable learning (depth)

2. is focused upon the gradual but secure success/achievements (length)

3. is a key of maintaining other leaderships (breadth)

4. is based on the values of social justice (justice)

5. is a way of generating and not depleting natural, human and material resources (diversity)

6. provides a space for the environment to flourish and develop (resourcefulness)

7. is a source of engaging people with their environment actively (conservation)

From this work of Hargreaves and Fink further models were derived by some of the scholars like Hill (2006), Davies (2009) and Hargreaves (2009) as mentioned by Lambart (2012). All of those discussed the role of market competition in the education sector that of public and private race as compared to the benefits of collaboration but Wolf (2011) declared the importance of collaboration in leadership as superior to thecompetition. As a product of all of the above-stated models of sustainable leadership, Lambart (2011) provided a crux of sustainable leadership in his model suggested it for education other than compulsory (continuing, further, higher. Post-compulsory). The summary of his sixstep model presented the image of sustainable development as; 
1. responsible for staff's continuous capacity building towards leadership and management expertise

2. empowering staff of all organizational level in order to ensure and spread sustainability throughout the strategic distributions

3. working in a special way of collaboration to keep organization close with community participation and welfare

4. providing with a linkage by developing achievable benchmarks and short targets of long-term goals

5. making staff capable of acquiring quick positive learning from their surroundings, environment and diversity by participating in societal collaboration and cohesion

6. strengthening the staff enough to learn from their past, understand, change and create a sustainable future

Keeping in view Lambert's model, the appraisal was developed to assess the level of transforming prospective teacher as sustainable leaders in higher education institutes; those were filled by the head of departments.

Some Aspects of a Sustainable Society (Forum for the Future, 2003)

Natural: $\quad$ In the extraction and manufacture of natural capital in a society, the substances involved in it would not exceed from surroundings' diversity/capacity in terms of its dispersion, absorption, recycling or human usage. The environment would be protected and enhanced in every manner.

Human: $\quad$ Personal standards, safety, health, development and learning should be at its highest level of standard and every individual of a society regardless of age should enjoy it. Everyone should participate in social interactions and relationships while there should present satiating opportunities of work, innovations and pastime for them.

Social: $\quad$ Governance and justice should be trusted and accessible. Large societies should share optimism in terms of purpose and values. Societal institutions should address preservation of natural resources, while every stakeholder in a society should be responsible for providing safe, secure and supporting living plus working opportunities. 
Manufactured: From raw material to end products, everything should be able to preserve natural resources and environmental health.

Financial: $\quad$ The financial capital used throughout the globe must represent the actual value of every resource; human, natural, social or manufactured and not the inflated one.

\section{Need of Sustainable Leadership}

Due to its maturity, the concept of sustainable leadership was mostly discussed at compulsory education level while one study could be found at further education level (Lambert, 2012). Wolf (2012) also looked the concept of vocational education. However, the ideas in those studies could be explored in order to transfer any possibility for post-compulsory and higher studies. The need of acquiring sustainable leadership had been discussed earlier as follows:

- There is a lack of quality leadership in elementary level of education; the reasons behind this are many, among them are job frustrations, low funding, and poor delivery of education (Hargreaves \& Fink, 2006).

- The leadership working in all levels of education is usually among the population who is extensively aged or are ageing; thus making a great shortage of updated experienced, skilful leaders on prominent leadership seats (Magnus, 2009).

- If an organization uses a wholesome approach for making developments in leadership; should not be based on short-term fixtures and amendments rather adopt long-lasting, durable changes keeping an eye on long-term continuing trajectories, so that whoever occupies a leadership post organization's function would not matter (Hargreaves \& Fink, 2006).

- Any initiative that would be taken by the organization in the name of change would affect in one way or other on overall management and its processes; that would create an environment of stress and frustration between staff (Robson, 1998; Elliot, 1996).

\section{Methodology}

This paper follows descriptive yet qualitative approach for collection and analysis of data. 25 Head of Departments from 5 universities present in Lahore was invited to take part in this study. Heads were interviewed 
for assessing their institutes' level at which they were exclusively or inclusively preparing their students as sustainable leaders and to judge the underlying situations for sustainability in their institutes.

\section{Development of Instrument}

The interview protocols for sustainability in higher education institutes were developed keeping in view the work and principles of Lambert (2011) it was applied in an educational perspective for this study. The protocols covered three pillars of sustainability i.e. environmental, social and economic and asking whether those were factors that a higher education institute usually able to involve or deliver in i.e. education \& research, university operations and external community. The interview protocol was validated by four experts in the related field. The tool was valid, certified by experts to measure the agreement of head's institute level in concocting students as sustainable leaders and to judge the underlying situations for sustainability in their institutes

\section{Results and Discussions}

The analyses of transcriptions of interviews were done through thematic analysis. Main themes were taken same as of sustainability pillars i.e. environment, society and economy. Each theme was broken into subcategories as per university inclusive or exclusive functionalities i.e. education and research, operations and community. Participants were also asked to indicate the level i.e. high, medium or low in embedding ESD in all above specified categories. Participants were found to be the faculty members of 3 public and 2 private universities.

\section{Environmental Aspects}

All the university campuses included in this study had fully developed infrastructure conducive for higher education, yet there were cases in which those cannot be considered as fully 'green' in terms of environmental sustainability. One of the public campuses there found a lack of student's sense of responsibility for disposing of their litter properly, while the other was considered at a medium level according to researchers' personal experience. On the contrary, researchers found both 
private campuses had highly clean in their infrastructure. Some of the other aspects were also taken into account under environmental aspects as: Education and research: All university campuses were declared by their head of departments as on medium level for education and conducting researches on environmental issues, as one of the public sector department head mentioned in his verbal descriptions...

...our faculty is trying to come up with a separate course especially meant for environmental protection or sustainable education... we are working on a proposal for making the course accepted by HEC...

While one of the private sector head of social sciences said, "we already have courses like environmental studies/ environmental education and cultural studies in which we are delivering a sense of getting green and sustainable for future..."

University Operations: One of the private university campuses declared their training regarding environmental protection as high while the other termed as low, thelogic the head mentioned in his short interview was that...

... we actually don't need such kind of environmental protection training for our campus, as you can see its infrastructure is so quite attractive that students usually don't spoil it rather enjoy their presence in such a landmark....

On the other hand, public sector campuses were at medium level for their training of environmental protections. As the department head of education showed interest in conducting short workshops and seminars on sustainable environmental protections.

... you are actually right, there must be ongoingtraining time to time for making our students habitual of not harming environment...

External Community: All universities mentioned to at medium level in preparing that groups of students who are actually able to protect or generate resources. The reason behind this was stated as....

The fact is that there found a sort of win-win situation or $50-50$ scenario for students to get job in which they are specialized, if they don't get their aspired job their frustrations make them forget unlikely of what they had learnt i.e. also keeping their surrounding clean or their peace of mind might also be disturbed... 


\section{Social Aspects}

University campuses included in this study had courses in one way or other related to social values, development, lifestyle, or professional development ultimately making the students for earning alivelihood for them and their families. Courses specifically in arts, humanities and social sciences are more or less depicting social aspects of sustainability. Following are the aspects described by the head of departments in their appraisals and interviews:

Education and Research: As described earlier social sciences, arts and humanities depict social aspects of the environment, while all of the university campuses of our study were offering social sciences. The level of education and research conducted in those campuses were high as described by their department heads. According to one of them,

...Social sciences discipline has the widest variety of subjects addressing every type of social aspects while our research journals are crowded with research studies conducted on social issues, yet there is still a room for researching on sustainable society...

University Operations and Community: Public sector university campuses declared their abilities to be low in making their students socially responsible, peaceful, loyal and delivering quality products, solutions and services.

We don't really know is it our environment or the content we are delivering in our courses that fail in enabling our students to expose them as socially responsible individuals in society. Only a few percentages of students are successfully fit in organizations in terms of quality products and services...

However, Private campuses claimed to produce socially responsible individuals, loyal and devoted to delivering what they exclaim; rated this ability as a medium.

\section{Economical Aspects}

Both types of universities claimed that they make their students able to make approachable decision making for their future. Yet the level varies among public and private ones. Private sector stood ahead of the public sector; as depicting them as 'high' in producing good decision 
makers. On the other side of a coin, apublic sector considered them in a medium category in producing good decision makers.

Various type of seminars are reported to be conducted by private campuses for a better life, acquiring financial strength and ways towards positivity of life thus making them proudly presenting as at medium of endeavour but this level is as low as ignorable in public sector campuses.

Private universities boast off to prepare their students for earning more than an average income as compared to majority population in a society.

...our name is a hallmark for our students which will surely help them in earning a lot more than their friends from other universities aspire...

Public sector campuses described them famous in producing two extremes of the society, on one hand, they are making individuals earn very fine but the percentage is very low, on the other hand, ahigh percentage is of strugglers.

\section{Conclusion and Suggestions}

This short study on 25 department heads of 5 higher education institutes overall shows that higher education has made some progress on sustainable development, particularly in trying to establish green campuses but legislative aspects are yet to be taken into considerations. In Pakistan, HEC is considered to be the main authority for implementing any change (HEC, 2016). Initiative for sustainable developments, education for sustainable development and creating sustainable leaders should be first introduced by Higher Education Commission so that a proper legislative framework could be developed for the purpose. Moreover, courses and subject areas should be upgraded and new must be introduced in the favour of sustainable development.

For any educational platform, sticking to sustainable development principles, goals, targets and objectives, is quite challenging, yet there is a global need due to issues of peace and citizenships. Sustainable development is a chance to revolutionize educational practices for global peace and environmental up gradation, for this purpose higher education of the developing countries should bring about comprehensive changes. In every subject area and course of studies of higher education, there should be integration with regard to three pillars, as they run in juxtaposition for ensuring sustainability and stability in one another. 
Judgments drew through results of this study, higher education institutes specifically public sector universities and degree colleges far lagged behind in attaining this kind of sustainability or producing sustainable leaders. Private sector role is encouraging in the sense; those were trying at their own to come up with such population of students who are logically responsible and firm in preserving as well as generating all three types of sustainable resources (social, economic, environmental).

This study also indicated that for a higher education institute, there is a need to integrate sustainability into all different functions and operations of the institute as well as higher education; for this purpose, HEC must develop an agenda compulsory for every HEI. As per indicated by heads, universities inclusively or exclusively are incorporating sustainability or some of its factors in their activities, as one of the heads of the department mentioned that...

... a few years back we had introduced a course in Masters in education that is named as Education for Sustainable Development in one of its semesters, I think this is a first step in developing sustainable leaders from our side. We also had conducted some master's thesis and research studies on this very area.....while healthy sports gala, culture preservation festivals were also a proof of our pacing towards spreading awareness of sustainability in our youth...

\section{Future Directions}

Future researchers can focus on barriers and major challenges in implementation and integration of sustainable development in our higher education. Or a whole new proposal could be researched and drafted to HEC for the training of students specifically as sustainable leaders regardless of subjects or disciplines. University faculty members should also transform themselves as sustainable leaders so that they can lead their youth for preparing for future sustainability demands, challenges and aspirations. The implicit attitude of universities towards sustainability should be transformed to explicit for imposing a direct impact on behaviours rather than indirect influences.

It would also be pertinent to target UNESCO and OECD for drawing their attention towards the role of education in generating sustainable leaders in developing countries; that have an impact on global economy and those countries that are more vulnerable towards peace and citizenship issues. 


\section{Acknowledgement}

The study was purely conducted in Educational context regarding the level of embeddedness in education for sustainable development and role of heads in preparing their students as sustainable leaders. Though the results supported by the literature (indicated at literature review section of the paper) but for the theoretical support, it is the dire need to replicate this study in a wide-ranging context. 


\section{References}

Bassey, M.O. (2010). Education for civic citizenship and social justice: A critical social foundations approach. Educ. Chang, 14: 247-257

Creswell, J. W. (2012). Educational research: Planning, conducting, and evaluating quantitative and qualitative research $\left(5^{\text {th }}\right.$ ed.). Upper Saddle River, NJ: Pearson Education.

Davies, B. (2009). The essentials of school leadership. London: Sage.

Eagleton, T. (1983). Literary theory: An introduction. Oxford: Basil Blackwell.

Elliott, G. (1996). Educational management and the crisis of reform in further education. Journal of Vocational Education and Training, $48(1), 5-23$.

Elliott, J. (1998). The Curriculum experiment. Meeting the challenge of social change. Milton Keynes: Open University Press.

Fullan, M. (2005). Leadership and sustainability. Thousand Oaks, CA: Corwin Press

Glickman, C.D. (2002). Leadership for learning: How to help teachers succeed. Alexandria, VA: Association for Supervision and Curriculum Development.

Hargreaves, A, \& Fink, D. (2006). Sustainable leadership. San Francisco, CA: John Wiley \& Sons.

Hargreaves, A., \& Fink, D. (2004). The seven principles of sustainable leadership. Alexandria, VA: Association for Supervision and Curriculum Development.

Hidalgo, A. L., Manuel, J. \& Fuentes, A. (2013). The development of basic competencies for sustainability in higher education: An educational model. US-China Education Review, 3(6), 447-458.

Hill, R. (2006) Leadership that lasts: Sustainable school leadership in the 21st century. London: Association of school and college leaders.

Husserl, E. (1931). Ideas: General introduction to pure phenomenology (D. Carr, Trans.). Evanston, IL: Northwestern University Press. 
Husserl, E. (1970). The crisis of European sciences and transcendental phenomenology (D. Carr, Trans.). Evanston, IL: Northwestern University Press.

Khalifa, M. A., \& Sandholz, S. (2012) Breaking barriers and building bridges through networks: An innovative educational approach to sustainability. International Journal of Environmental \& Science Education,3(3).

Lambert, S. (2011). Sustainable leadership and the implication for the general further education college sector. Journal of Further and Higher Education, 35(1), 131-148.

Lambert, S. (2012). The Perception and implementation of sustainable leadership strategies in further education colleges. Journal of Leadership Education. 11(2).

Magnus, G. (2009). Dependency time-bomb. Guardian, 4th February 2010.

Manen, M. (1990). Researching lived experience: Human science for an action sensitive pedagogy. Albany: State University of New York Press.

Marshall, C., \& Rossman, G. B. (2010). Designing qualitative research ( $5^{\text {th }}$ ed.). Thousand Oaks, CA: Sage.

Merleau-Ponty, M. (1956). What is phenomenology? Cross Currents, 6, 59-70.

Moustakas, C. (1994). Phenomenological research methods. Thousand Oaks, CA: Sage.

Mustaq, N. \& Azeem, M. (2012). Conceptual understanding of sustainable development. Academic Research International,2 (2).

OECD. (2011). 19 $9^{\text {th }}$ session of UN Commission on Sustainable Development.

Owens, R.G., \& Valesky, T.C. (2011). Organizational behavior in education: Leadership and school reform. $\left(10^{\text {th }}\right.$ ed.). Pearson.

Polkinghorne, D. E. (1989). Phenomenological research methods. In R. S. Valle \& S. Halling (Eds.), Existential phenomenological perspectives in psychology 41-60. New York: Plenum Press. 
Rauch, F. (2002). The potential for sustainable development for reform in schools. Environmental Education Research, 8(1), 43-51.

Robson, J. (1998). A profession in crisis: status, culture and identity in the further education college. Journal of Vocational Education and Training, 4(50), 585-607.

Scott, W. \& Gough, S. R. (2004) Education and sustainable development in UK Universities: a critical exploration post-Rio; In P Blaze Corcoran \& AEJ Wals (Eds.) Higher education and the challenge of sustainability: problematics, practice, and promise, dordrecht:Kluwe

Spiegelberg, H. (1982). The phenomenological movement $\left(3^{\text {rd }}\right.$ ed.). The Hague, Netherlands: Martinus Nijhoff.

Stockholm Declaration on the Human Environment, in Report of the United Nations Conference on the Human Environment, (1972). UN Doc.A/CONF.48/14, at 2 and Corr.1.

Stoll, L., Fink, D., \& Earl, L. (2002). It's about learning (and it's about time). London: Routledge/Falmer.

UNESCO (2012). UN Resolution adopted by the General Assembly on 27 July 2012. The document refers to ESD and the role of universities in sustainable development. Education for Sustainable Development. Available at:www.unesco.org/new/en/education/ themes/leading-the-international-agenda/education-forsustainabledevelopment

Vandenberg, D. (1997). Phenomenological research in the study of education. In D. Vandenberg (Ed.), Phenomenology \& education discourse, (pp.3-37). Johannesburg, South Africa: Heinemann.

WCED, (1987). Our common future, report of the world commission on environment and development, Oxford.

Wiek, A. (2012). Core competencies in sustainability. 9th Annual ITdNet Meeting, March 2-3. Leuphana Sustainability Summit 2012, Lüneburg, Germany.

Wiek, A., Withycombe, L., Redman, C., \& Banas M. S. (2011). Moving forward on competence in sustainability research and problem solving. environment: Science and policy for sustainable development,53(2), 3-13. doi:10.1080/00139157.2011.554496 
Willard, M., Wiedmeyer, C., Flint, R. W., Weedon, J. S., Woodward, R., Feldman, I., \& Edwards, M. (2010). The sustainability professional: 2010 Competency Survey Report. International Society of Sustainability Professionals (ISSP).

Wolf, A. (2011). Review of vocational education - The wolf report. London: Stationary Office.

\section{Citation of this Article:}

Khan, S., \& Khan, A.M. (2018). A phenomenological study of education for sustainable development in higher education of Pakistan. Pakistan Journal of Education, 35(2), 117-136.

$\begin{array}{ll}\text { Received on: April } & 05,2017 \\ \text { Revised on: May } & 03,2018 \\ \text { Accepted on: July } & 06,2018\end{array}$

